\title{
First detection of Bursaphelenchus luxuriosae associated with Pinus pinaster in Portugal and in Europe
}

Article in Forest Pathology · July 2016

DOI: 10.1111/efp.12296

CITATIONS

0

4 authors:
READS

94

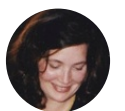

Maria Lurdes Inacio

Instituto Nacional de Investigação Agrária e V..

24 PUBLICATIONS 104 CITATIONS

SEE PROFILE

\section{Manuel Mota}

Universidade de Évora

144 PUBLICATIONS $\quad 1,519$ CITATIONS

SEE PROFILE

\section{Filomena Nóbrega}

Instituto Nacional de Investigação Agrária e ... 93 PUBLICATIONS 34 CITATIONS

SEE PROFILE

\section{Paulo Vieira}

Virginia Polytechnic Institute and State Univ... 74 PUBLICATIONS 1,038 CITATIONS

SEE PROFILE

Some of the authors of this publication are also working on these related projects:

Project

Project

Virus-vector nematodes, Fam. Longidoridae and root lesion nematode Pratylenchus penetrans View project

Bacterial endophytes association with plant parasitic nematodes: Bursaphelenchus xylophilus and its associated bacteria as a case study View project 


\title{
First detection of Bursaphelenchus luxuriosae associated with Pinus pinaster in Portugal and in Europe
}

\author{
M. L. Inácio ${ }^{1}$ | F. Nóbrega ${ }^{1}$ | M. Motat ${ }^{2,3}$ | P. Vieira ${ }^{2}$
}

${ }^{1}$ Instituto Nacional de Investigação Agrária e Veterinária (INIAV, I.P), Quinta do Marquês, Oeiras, Portugal

${ }^{2}$ Lab. Nematologia/ICAAM - Instituto de Ciências Agrárias e Ambientais Mediterrânicas, Universidade de Évora, Évora, Portugal

${ }^{3}$ Departamento de Ciências da Vida, Universidade Lusófona de Humanidades e Tecnologias, Lisboa, Portugal

\section{Correspondence}

Maria L. Inácio, Instituto Nacional de Investigação Agrária e Veterinária (INIAV, I.P), Quinta do Marquês, Oeiras, Portugal. Email: lurdes.inacio@iniav.pt

Editor: J. Hantula

\begin{abstract}
Summary
During a field survey carried out on symptomatic maritime pine trees (Pinus pinaster) in Góis, central Portugal, Bursaphelenchus luxuriosae was isolated for the first time in Portugal, and in Europe. Identification of the nematodes was based on morphological characters and molecular analyses for this species. The general morphology of both females and males is in agreement with the original description for B. luxuriosae, namely the typical morphology of the male spicules and the conspicuous morphology of female tail. Species identification was confirmed through sequencing of the ITS rDNA region and the fragment spanning the D2/D3 domain of the $28 \mathrm{~S}$ rDNA gene. This species belongs to the xylophilus-group and is the third species in this group known in Portugal. The nematodes were retrieved in small numbers $(<100$ nematodes/100 g dry wood), and no insect vector association could be established.
\end{abstract}

\section{1 | INTRODUCTION}

Bursaphelenchus Fuchs, 1937 is a large genus currently comprising over 100 valid species, most of which are wood-inhabiting and fungal-feeding nematodes colonizing mainly conifer trees (Hunt, 2008). Because of the detection of Bursaphelenchus xylophilus, the pinewood nematode (PWN), in Portugal in 1999, the national forestry authority has carried out intensive annual monitoring surveys in pine forests, with several thousands of wood samples collected per year. To date, these surveys have enabled the identification of eleven Bursaphelenchus species in the country (B. antoniae, B. fungivorus, B. hellenicus, B. leoni, B. minutus, B. mucronatus, B. pinasteri, B. pinophilus, B. sexdentati, B.tusciae and B.xylophilus) (Fonseca, Cardoso, Moron-Lopez, \& Abrantes, 2014; Fonseca, Moron-Lopez, \& Abrantes, 2012; Mota et al., 1999; Penas, Bravo, Naves, Bonifácio, \& Mota, 2006; Penas, Correia, Bravo, Mota, \& Tenreiro, 2004; Penas, Metge, Mota, \& Valadas, 2006; Vieira \& Mota, 2013), mainly associated with maritime pine trees (Pinus pinaster), with only two in the xylophilus-group, namely B. xylophilus and B. mucronatus (Mota et al., 1999; Penas et al., 2004). More recently, B. xylophilus was also detected for the first time in Austrian pine (Pinus nigra) in Portugal (Inácio et al., 2015).

During a field survey carried out in 2014 for the study of the mycoflora associated with symptomatic maritime pine trees (symptoms included needle discoloration or wilting) in the central area of Portugal where the pinewood nematode is known to occur (Gois, Coimbra), specimens of B. luxuriosae Kanzaki \& Futai, 2003; a species of the xylophilus-group, were isolated and characterized morphologically. Phylogenetic analysis based on ITS sequences (Burgermeister, Metge, Braasch, \& Buchbach, 2005) and D2/D3 expansion region of the large subunit (LSU) rRNA gene (Kanzaki \& Futai, 2003) confirmed this species identification. Therefore, we report herein for the first time the occurrence of B. luxuriosae associated with Pinus pinaster in Portugal, and to our knowledge in Europe.

\section{2 | MATERIAL AND METHODS}

\section{1 | Wood sampling and nematode extraction}

In April/May 2014, a survey was carried out in a stand of Pinus pinaster in Góis (Coimbra, Portugal), with the objective of studying the mycoflora associated with trees infected with Bursaphelenchus xylophilus. For that purpose, thirteen trees (approximately 35-years old) were selected and felled. From each tree, three wood discs (30-35 cm diameter; $5 \mathrm{~cm}$ thick) were collected from two different heights (breast height and top of the trunk) of the main trunk and 
cut in $1 \mathrm{~cm}^{3}$ squares for both fungal isolation and nematode extraction. Wood pieces for nematode extraction were kept in plastic bags until processed. Nematodes were extracted using the "tray" method (Whitehead \& Hemming, 1965) and processed within 48 hr. All nematode stages of Bursaphelenchus species isolated from individual wood discs/trees were cultured on mycelia of a non-sporulating strain of Botrytis cinerea on potato dextrose agar (PDA), at $25^{\circ} \mathrm{C}$. After 3 weeks, nematodes were washed from the fungal culture with sterilized distilled water and collected for morphological and molecular studies. Morphological identification was based on the main diagnostic features for the genus Bursaphelenchus (Braasch, Burgermeister, \& Gu, 2009; Braasch \& Schönfeld, 2015; Ryss, Vieira, Mota, \& Kulinich, 2005;): shape of the spicules, presence of vulval flap, female tail shape and number of incisures in the lateral field. At least, 10 specimens were heat-killed and placed in a drop of water on a glass slide for morphological characterization using an Olympus BX-51 bright field light microscope (Hamburg, Germany) and photographed with an Olympus DP10 digital camera.

\section{2 | Molecular analysis}

Total genomic DNA was isolated from six hand-picked nematode specimens. Nematodes were transferred to an Eppendorf tube with $10 \mu \mathrm{l}$ of sterilized water, frozen in liquid nitrogen and homogenised with a micropestle (Eppendorf, Hamburg, Germany). The homogenate was incubated at $56^{\circ} \mathrm{C}$ in lysis buffer and $100 \mu \mathrm{g} \mathrm{ml}^{-1}$ proteinase $\mathrm{K}$ for $1 \mathrm{hr}$. After incubation, total genomic DNA extraction was performed using the DNeasy Blood \& Tissue Kit (Qiagen, Hilden, Germany) following the manufacturer's instructions. DNA quantity and purity were checked using a NanoDrop 2000 UV-Vis Spectrophotometer (Thermo Fisher Scientific, MA, USA). Two DNA regions were amplified by Polymerase Chain Reaction (PCR): the ITS region, amplified using the forward primer ITS-5 (5'-GGAAGTAAAAGTCGTAACAAGG-3') and reverse primer ITS-4 (5'-TCCTCCGCTTATTGATATGC-3') (White, Bruns, Lee, \& Taylor, 1990), and the D2/D3 region, amplified using the primers D2A (5'-ACAAGTACCGTGGGGAAAGTTG-3') and D3B (5'-TCGGAAGGAACCAGCTACTA-3') (De Ley et al., 2005). PCR reactions were performed in a $25 \mu \mathrm{l}$ final volume using the Promega GoTaq Flexi DNA Polymerase kit (Promega, Madison), containing
$1 \mu \mathrm{l}$ template DNA, $5 \mu \mathrm{l}$ GoTaq Flexi PCR buffer (Promega, Madison), $1.5 \mathrm{mmol} \mathrm{L}^{-1} \mathrm{MgCl}_{2}, 0.20 \mathrm{mmol} \mathrm{L}^{-1}$ each dNTPs, $1.25 \mathrm{U}$ GoTaq Flexi DNA Polymerase (Promega, Madison) and $0.4 \mu \mathrm{mol} \mathrm{L}^{-1}$ of each primer in a Biometra TGradient thermocycler (Biometra, Göttingen, Germany). Thermal cycling conditions were as follows: initial denaturation at $94^{\circ} \mathrm{C}$ for $5 \mathrm{~min}$, followed by 35 cycles of $2 \mathrm{~min}$ at $94^{\circ} \mathrm{C}$, annealing at $55^{\circ} \mathrm{C}$ for $1 \mathrm{~min}$ and extension at $72^{\circ} \mathrm{C}$ for $1 \mathrm{~min}$, followed by a final elongation for $10 \mathrm{~min}$ at $72^{\circ} \mathrm{C}$. The amplified products were loaded onto a $1.5 \%$ agarose gel containing $0.5 \mathrm{\mu g} \mathrm{ml}^{-1}$ ethidium bromide and $0.5 \times$ Tris-borate-EDTA (TBE) running buffer and electrophoresed at $5 \mathrm{~V} \mathrm{~cm}^{-1}$. Amplifications were visualized using the VersaDoc Gel Imaging System (Bio-Rad, USA). PCR products were cleaned using the GeneJET PCR Purification Kit (Fermentas, Germany) according to the manufacturer's protocol. Amplicons were sequenced in forward direction at STABVida Sequencing Laboratory (Lisbon, Portugal) on a DNA analyzer ABI PRISM 3730xI (Applied Biosystems). Nucleotide sequences were edited and analyzed using BioEdit v7.2.0 (Hall, 2007). The resulting ITS and D2-D3 rDNA sequences were compared against a set of reference sequences from different species of Bursaphelenchus selected from GenBank (NCBI) to cover a range of species that comprise the xylophilus-group. The tree topology was obtained by neighbour-joining (NJ) analysis with 1000 bootstrap replications using CLC Main Workbench v. 7 software.

\section{3 | RESULTS AND DISCUSSION}

From a total of 13 symptomatic maritime pine trees sampled from a pine stand in Gois, Coimbra, Portugal, six trees were positive for the pinewood nematode, Bursaphelenchus xylophilus (data not shown), while one of the trees exhibiting slight discoloration of the needles produced nematodes of an unreported species in the xylophilus-group for Portugal and Europe, and herein characterized. The nematodes were retrieved in small numbers ( $<100$ nematodes/100 g wood, dry weight). No nematodes or free-living nematodes only were recovered from the remaining six trees (data not shown).

Morphologically, the specimens of the unreported species of the xylophilus-group (Fig. 1), followed the main characters of the original description of B. luxuriosae (Kanzaki \& Futai, 2003), that is females
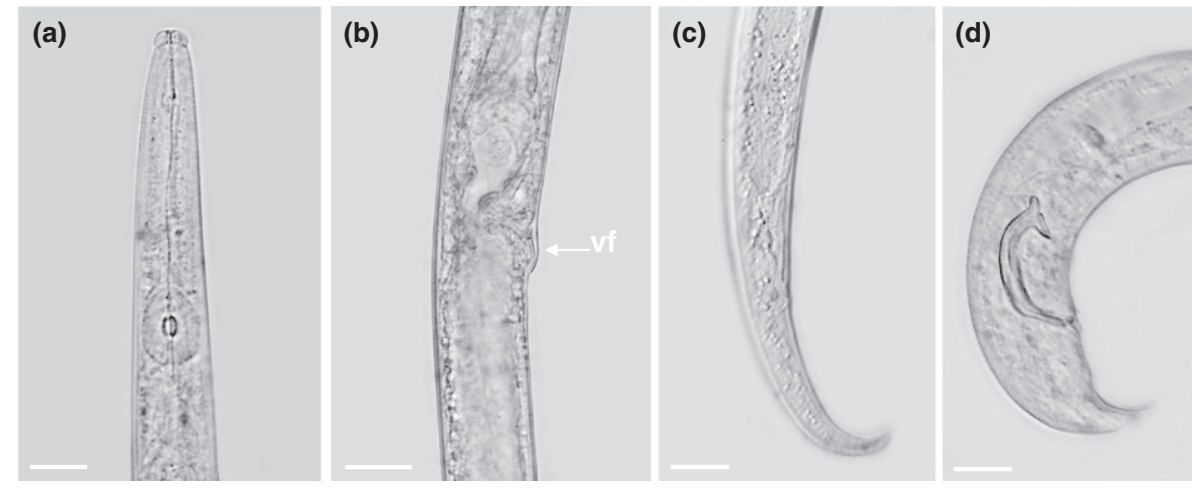

FIGURE 1 Light microscope observations of Bursaphelenchus luxuriosae isolated from Pinus pinaster in Góis (Coimbra). (a) anterior region; (b) vulva region (vf: vulval flap); (c) female tail; (d) male tail. Scale bars: $10 \mu \mathrm{m}$ 
with a long vulval flap (Fig. 1b); females (as well as juveniles) with a very conspicuous and distinctive long tail, tapered and strongly ventrally recurved when heat-killed, with an irregular and roughened dorsal contour approaching the tip and an irregular terminus (Fig. 1c); males presented long spicules, large and arcuate with pointed rostrum and terminal cucullus (Fig. 1d); male tails with the typical seven papillae (one single ventral pre-anal papilla, one pre-anal pair just before the cloacal slit, and two post-anal pairs of papillae, adjacent to each other and localized immediately anterior to the bursa), and both males and females presenting four lines in the lateral field. Although species belonging to xylophilus-group present similar morphological features, B. luxuriosae can be differentiated from B. xylophilus, as females of B. xylophilus present a broad cylindrical-rounded tail without mucro, or in some populations a broad cylindrical-rounded tail with mucro (Braasch et al., 2009; Braasch \& Schönfeld, 2015; Ryss et al., 2005), versus the distinctive long, tapered and strongly recurved tail in B. luxuriosae.

To validate and complement the morphological analyses, a molecular analysis was performed by sequencing both the ITS and D2/D3 rDNA loci. The sequences obtained by each pair of primers were deposited to GenBank database (NCBI) under the accession numbers KU341100 and KU341101, respectively. Amplification of the ITS region of these specimens (using the ITS- 5 and ITS-4) resulted in a PCR product of $655 \mathrm{bp}$, containing partial ITS-1, 5.8S, ITS-2 and partial $28 \mathrm{~S}$ region of the ribosomal DNA. The molecular phylogenetic status of the resulting ITS sequence is presented in Figure 2, showing the cluster of the different populations of $B$. luxuriosae, including the Portuguese isolate, among other species of the xylophilus-group. Based upon the full-length D2/D3 LSU region a fragment of $741 \mathrm{bp}$ was obtained for the specimens collected in Portugal (Fig. S1), revealing $100 \%$ similarity with sequences deposited for $B$. luxuriosae isolated in Japan (AB299228 and AM396571), and further confirming the species identification of the Portuguese isolate.

Bursaphelenchus luxuriosae was previously identified and reported in Japan alone (Gose, Nara prefecture), associated with the cerambycidae beetle, Acalolepta luxuriosa (Bates) (Coleoptera: Cerambycidae) emerging from Aralia elata (Miq.) Seem. (Araliaceae) (Kanzaki \& Futai, 2003). The potential pathogenicity of $B$. luxuriosae was previously evaluated on both Pinus densiflora and P. thunbergii using 3-year-old seedling (Kanzaki, Aikawa, Maehara, \& Ichihara, 2011). Although, B. luxuriosae could induce some damage to tracheal tissue of $P$. thunbergii, none of the seedlings tested died or displayed the wilting symptoms typical of the PWN. Interestingly, B. luxuriosae and B. doui are species within the xylophilus-group showing an entomoparasitic form, suggesting that the parasitic adult stage of these two species might have occurred independently as autapomorphy of each species (Kanzaki, Maehara, Aikawa, \& Nakamura, 2013).

The occurrence of this species in Portugal might be seen as unexpected, as the members of Acalolepta are all found in the Indomalaya ecozone, distributed in Southeast Asia and in Australia, mainly associated with broad-leaved forests. However, other species in this genus, such as A. sejuncta (Bat), are able to colonize both deciduous and coniferous trees (Cherepanov, 1990). More recently, A. sejuncta was detected associated with living plants of Taxus cuspidata imported from Japan to Germany, which raised a quarantine alert and a pest risk analysis in Germany; this species is currently a focus of plant quarantine by EPPO (EPPO, 2014). It is difficult to ascertain whether $B$. luxuriosae was introduced, together with its insect vector, or already occurred as a native species. However, the finding of $B$. luxuriosae could be an indicator for introduction of the vector beetle as well in Portugal. It is worth noting that the presence of suitable conditions will enable the establishment of this particular beetle species in the EU, and colonization of trees may be expected.

Finding B. luxuriosae demonstrates the wide dissemination of Bursaphelenchus species, and their high plasticity, enabling establishment in different geographical areas and colonization of different types of host trees. Following the several thousands of pine wood samples processed since the detection of the PWN in Portugal, this constitutes the first report and occurrence of B. luxuriosae in Portugal, and in Europe, as well as its natural association with a conifer tree.

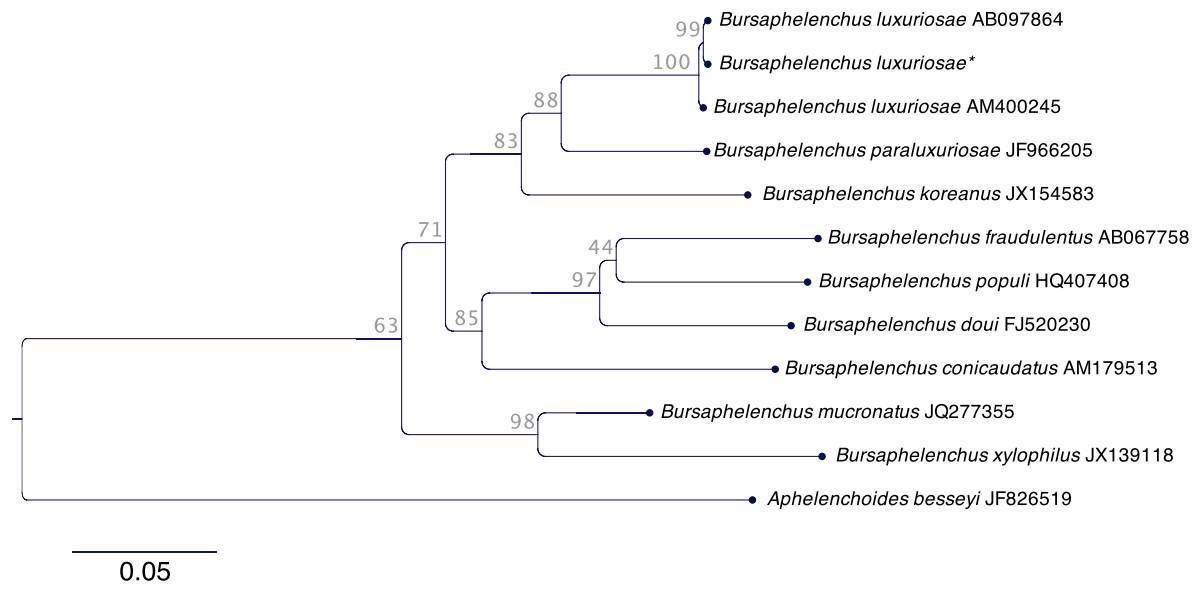

FIGURE 2 Phylogenetic relationships of Bursaphelenchus luxuriosae isolate collected from Portugal (highlighted with an asterisk) and other geographical regions (Japan), including other species of the xylophilus-group, based on the sequence alignment of the ITS region of the rDNA. The phylogram was generated by Neighbour-Joining analysis with 1000 bootstrap replication. Bootstrap values are indicated at the nodes. Scale bar = substitutions/site 
Efforts should be stepped up to determine the insect vector for B. luxuriosae in Portugal, maintaining close surveillance for the presence of this nematode in samples from the national survey programme. In case of recurrent findings of species of the genus Acalolepta in imports into the EU, a survey of nematodes associated with these beetles should be considered to determine the presence of B. luxuriosae or other Bursaphelenchus species.

\section{ACKNOWLEDGEMENTS}

This work was partially supported by National Funds through FCT (Fundação para a Ciência e a Tecnologia) under the FCT-project MICRONEMA (PTDC/BIA-MIC/3768/2012). The authors thank Margarida Fontes, of INIAV's laboratory of Nematology, for her technical assistance.

\section{REFERENCES}

Braasch, H., Burgermeister, W., \& Gu, J. (2009). Revised intra-generic grouping of Bursaphelenchus Fuchs, 1937 (Nematoda: Aphelenchoididae). Journal of Nematode Morphology and Systematics, 12, 65-88.

Braasch, H., \& Schönfeld, U. (2015). Improved morphological key to the species of the xylophilus-group of the genus Bursaphelenchus Fuchs, 1937. EPPO Bulletin, 45, 73-80.

Burgermeister, W., Metge, K., Braasch, H., \& Buchbach, E. (2005). ITS-RFLP patterns for differentiation of 26 Bursaphelenchus species (Nematoda: Parasitaphelenchidae) and observations on their distribution. Russian Journal of Nematology, 13, 29-42.

Cherepanov, A. I. (1990). Cerambycidae of northern Asia. Vol. 3, Lamiinae, Part 1 (pp. 300) New Delhi: Amerind Publishing Co. Pvt. Ltd..

De Ley, P., De Ley, I. T., Morris, K., Abebe, E., Mundo-Ocampo, M., Yoder, M., Thomas, W. K. (2005). An integrated approach to fast and informative morphological vouchering of nematodes for applications in molecular barcoding. Philosophical Transactions of the Royal Society of London. Series B, Biological sciences, 360, 1945-1958.

EPPO. (2014). EPPO report on notifications of non-compliance. EPPO Reporting Service - Pests and Diseases. 5, 10.

Fonseca, L., Cardoso, J. M. S., Moron-Lopez, J., \& Abrantes, I. (2014). Bursaphelenchus fungivorus from Pinus pinaster bark in Portugal. Forest Pathology, 44, 131-136.

Fonseca, L., Moron-Lopez, J., \& Abrantes, I. (2012). Bursaphelenchus fungivorus and B. minutus associated with Pinus pinaster bark in Portugal. In Abstracts of the 31st International Symposium of the European Society Nematologists. 23-27 September, Adana, Turkey, pp. 48.

Hall, T. (2007). BioEdit: Biological sequence alignment editor for Win95/98/ NT/2K/XP. Retrieved from http://www.mbio.ncsu.edu/BioEdit/bioedit.html.
Hunt, D.J. (2008). Achecklist of the Aphelenchoidea (Nematoda: Tylenchina). Journal of Nematode Morphology and Systematics, 10, 99-135.

Inácio, M. L., Nóbrega, F., Vieira, P., Bonifácio, L., Naves, P., Sousa, E., \& Mota, M. (2015). First detection of Bursaphelenchus xylophilus associated with Pinus nigra in Portugal and in Europe. Forest Pathology, 45, 235-238.

Kanzaki, N., Aikawa, T., Maehara, N., \& Ichihara, Y. (2011). An inoculation experiment of Japanese Bursaphelenchus nematodes on Japanese black and red pine, Pinus thunbergii and P. densiflora. Journal of Forest Research, 16, 325-330.

Kanzaki, N., \& Futai, K. (2003). Description and phylogeny of Bursaphelenchus luxuriosae n. sp. (Nematoda: Aphelenchodidae) isolated from Acalolepta luxuriosa (Coleoptera: Cerambycidae). Nematology, 5, 565-572.

Kanzaki, N., Maehara, N., Aikawa, T., \& Nakamura, K. (2013). An entomoparasitic adult form in Bursaphelenchus doui (Nematoda: Tylenchomorpha) associated with Acalilepta fraudatrix. Journal of Parasitology, 99, 803-815.

Mota, M., Braasch, H., Bravo, M. A., Penas, A. C., Burgermeister, W., Metge, K., \& Sousa, E. (1999). First report of Bursaphelenchus xylophilus in Portugal and in Europe. Nematology, 1, 727-734.

Penas, A. C., Bravo, M. A., Naves, P., Bonifácio, L., \& Mota, M. (2006). Species of Bursaphelenchus Fuchs, 1937 (Nematoda: Parasitaphelenchidae) and other nematode genera associated with insects from Pinus pinaster in Portugal. Annals of Applied Biology, 148, 121-131.

Penas, A. C., Correia, P., Bravo, M. A., Mota, M., \& Tenreiro, R. (2004). Species of Bursaphelenchus Fuchs, 1937 (Nematoda: Parasitaphelenchidae) associated with maritime pine in Portugal. Nematology, 6, 437-453.

Penas, A. C., Metge, K., Mota, M., \& Valadas, V. (2006). Bursaphelenchus antoniae sp. n. (Nematoda: Parasitaphelenchidae) associated with $\mathrm{Hy}$ lobius sp. from Pinus pinaster in Portugal. Nematology, 8, 659-669.

Ryss, A., Vieira, P., Mota, M., \& Kulinich, O. (2005). A synopsis of the genus Bursaphelenchus Fuchs (Nematoda: Parasitaphelenchidae) with a key to species. Nematology, 7, 393-458.

Vieira, P., \& Mota, M. (2013). On the track of Bursaphelenchus pinophilus Brezski and Baujard, 1967 (Nematoda: Aphelenchoididae) in Portugal. Forest Pathology, 43, 433-436.

White, T. J., Bruns, T., Lee, S., \& Taylor, J. (1990). Amplification and direct sequencing of fungal ribosomal RNA genes for phylogenetics. In M. A. Innis, D. Gelfand, J. J. Sninsky, \& T. J. White (Eds.), PCR Protocols: a guide to methods and applications (pp. 315-322). San Diego: Academic Press.

Whitehead, A. G., \& Hemming, J. R. (1965). A comparison of some quantitative methods of extracting small vermiform nematodes from soil. Annals of Applied Biology, 55, 25-38.

\section{SUPPORTING INFORMATION}

Additional Supporting Information may be found online in the supporting information tab for this article. 